\title{
The role of molecular imaging in precision radiation therapy for target definition, treatment planning optimisation and quality control
}

\author{
Giovanni Lucignani1, 2, Barbara A. Jereczek-Fossa1, Roberto Orecchia1, 2 \\ 1 Unit of Molecular Imaging, Department of Radiation Oncology, European Institute of Oncology, Milan, Italy \\ 2 Institute of Radiological Sciences, University of Milan, Milan, Italy \\ Published online: 5 May 2004 \\ (C) Springer-Verlag 2004
}

Eur J Nucl Med Mol Imaging (2004) 31:1217

DOI 10.1007/s00259-004-1579-9

The online version of the original article can be found at http://dx.doi.org/10.1007/s00259-004-1517-x

Giovanni Lucignani $(\bowtie)$

Unit of Molecular Imaging, Department of Radiation Oncology,

European Institute of Oncology, Via Ripamonti 435,

20141 Milan, Italy

e-mail: giovanni.lucignani@unimi.it

Tel.: +39-02-57489037

\section{Eur J Nucl Med Mol Imaging (2004) 10.1007/s00259-004-1517-x}

In the section "Merging molecular and anatomical imaging for precision radiation therapy", the first sentence of the third paragraph should be:

The use of a nucleoside, thymidine, has been evaluated for the assessment of cell proliferation based on its incorporation in DNA. 